\title{
On the Instructional Design of Online Courses for Application-oriented College Students from the Perspective of Learners
}

\author{
Chow Xiaofen ${ }^{1}$, Cheung Qingying ${ }^{2}$, Wong Yong ${ }^{3}$ \\ ${ }^{1,3}$ Wuhan Technology and Business University, Wuhan 430065, China \\ ${ }^{2}$ Wuhan University of Technology, Wuhan 430065, China
}

\begin{abstract}
Recently, the construction of online courses is considered as one of the main teaching reform activities in colleges. The thesis stands from the view of scholars to come up with an argument that the construction of online courses is supposed to pay more attention to the difference between scholar's culture and learning purposes, to accurately grasp scholar's demand and to construct and perfect the online course from teaching and learning resources design, learning activity design and learning assessment design with the principle of combination of science and practice. Besides, the construction process needs to establish feedback system through scholar's comment on each indicator of instructional design for online courses so as to constantly update and optimize the courses and fully carry forward their advantages.
\end{abstract}

Keywords-Learners; Online course; Instructional design; Application-oriented colleges

\section{INTRODUCTION}

Massive Open Online Courses, namely MOOCs, have boomed around the globe since 2012, which pushes online education becoming the hot topic in higher education. The advanced internet and information technologies such as social network, cloud computing, artificial intelligence and big data provide a firm and broad platform for the development of online courses. With online learning, all the scholars are able to break the limitations of space and time to share excellent educational resources through network and further realize massive learning and personal learning.

In recent years, application-oriented colleges have actively introduced and promoted online courses. Nowadays, the teaching of online courses develops rapidly and makes an outstanding achievement in numbers. While due to the rooted traditional teaching pattern, the awareness of online courses' teaching and learning has not been completely established among teachers and students. Students in application-oriented college are weak at initiative, enthusiasm and concentration in comparison with those who are in academic college. Because of higher requirements of autonomous learning ability for online courses on scholars, application-oriented college should take student's characteristics into consideration when adopting online learning under students-centered construction, think highly of instructional design and give full play to advantages

Foundation item: The Subject of "Research on the Instructional Design of Online Courses for Application-oriented College Students" for the Educational and Scientific Planning of Hubei Province in 2018 (Project No. 2018GB121) of online courses to improve the effect of teaching.

\section{RESEARCH STATUS AT HOME AND ABROAD}

As the birthplace of online courses, America has more and more researches on MOOC, while at present, the number of research results on MOOC instructional design is still insufficient. Adolfo Plasencia and Natalia Navas (2014) suggested that although MOOC online courses have changed learning paradigms and practice, it cannot replace traditional classroom teaching, for its focus on mixed learning mode[1]. Kate O’Connor (2014) illustrated the course redesign via MOOC platform from the point of system establishment [2]. Adam Driscoll and his team (2012) conducted a comparative research of the effects between traditional teaching and online courses. Adam believed that online teaching can perform the same as traditional ones and achieve equal effect and satisfaction by adopting effective teaching methods to precede the class [3]. Finger and other scholars discussed the quality of MOOC courses from students' perspective, suggesting that the quality of MOOC courses has a closely relations with its business mode, intellectual property problem, courses design (including assessment design) and credit certification [4]. On account of "the concept of life cycle for E-learning design", King $\mathrm{C}$ and Kelder $\mathrm{J}$ A considered that learning types, teaching and learning activities and data are crucial means for massive teaching[5].

Domestic scholars not only do research on the theories about development and design of online courses but also conduct it from the reality the online course design and development. Some of them analyzed the problems and solutions of online courses from a macro perspective. Others started with methods and principles of online courses' development and design, exploring the problems in design and development in details. Luo Fang, one of the scholars, made an analysis on the process of MOOC courses and drew a conclusion about the courses features from video, quiz and discussion, and put forward that MOOC courses design should adhere to principles of humanism, behaviorism and constructivism [6]. In "Understanding the Course--The Inner Logic of MOOC Teaching Design”, Wu Nan who made a definition on the connotation of MOOC teaching design in line with his own comprehension about courses theory, proposed that MOOC teaching should be designed to create a platform where its significance and spiritual life can be shown and 
advocated that this design should take into consideration the expectation and needs that stem from scholars' "bias" to establish the targets [7].

The learners are regarded as "the most important service objects"," the most direct client" and "the most qualified courses reviewers". Supported by this idea, the satisfaction from students becomes the criteria to evaluate the quality of online courses. There are some researches on the quality assessment about online course from learners' perspective. For example, Wong Meijing who conducted a comparative analysis of structures and performances of platform homepages, courses homepage, videos and BBS among Coursera, edX, Futureleam and Iversity made a suggestion for MOOC construction from a learners' view [8]. Chan Zhihua designed and applied useful index system of online courses from the experience of learners [9]. Zhang You carried out a research on availability of online teachers training courses based on the users experience [10]. Bai Xiaojing also analyzed the teaching quality of online courses [11]. Liu Mingzhuo and Zhu Zhiting studied the teaching structures and activities of MOOCs and launched 7 teaching types for MOOCs based on years of experiences and researches on online courses construction [12]. Hu Qintai and Lin Xiaofan, after carrying out multi-aspects analysis of MOOCs both home and abroad, revealed the relationship between MOOC teaching and service science based on service science theory, investigated and analyzed the service demands on MOOCs from learners and combed through the outstanding issues[13].

\section{PRINCIPLES OF INSTRUCTIONAL DESIGN FOR ONLINE} COURSES

\section{A. Learners' needs oriented}

One of the advantages of online courses is the clear of limitation of time and space for learning, providing study opportunities for learners at different levels from around the world. However, most courses constructers ignore different educational backgrounds and learning ability of learners and fail to create a learning environment in accordance with learners' demand and consequently impose a negative effect on their enthusiasm and sustainability. For application-oriented colleges, in particular, there are higher requirements on instructional design as a result of the learners' condition. Only by fully exerting the strengths of online courses, can colleges achieve the goals to cultivate talents. Since online courses are learner-oriented, it's critical to obtain satisfactory teaching performance by meeting learners' demands and attracting their attention.

\section{B. Combine science and practice}

The instructional design for online course abides by the principle of combining science and practice and teaching goals should be put at the first place when constructing online courses. While meeting learners' needs, we should persist in science, and assessment index system of online courses teaching design which is qualified both home and abroad in application-oriented colleges should be taken as a standard. Modern informational technology should be adapted to design teaching activities with high operability and adaptability so as to share the educational resources.

\section{Diversified interactive instructional design}

Effective and high-quality interaction is the catalyst to stimulate learner's interest. While the online course breaks through the time and space constraints of teaching, it also brings the problem of interactive instructional design of online courses. Traditional teaching can let teacher communicate with learners face to face, grasp the status of learners at any time, flexibly use various interactive ways to attract students' attention, convey knowledge structure and emphasize important and difficult points. However, online courses can't use face-to-face communication and interaction, and can' $t$ accurately grasp the learner's status. Therefore, diversified interactive instructional design has become an important means to solve interactive problems and attract the learner's attention in the process of online teaching. If there is a lack of interaction in the online course, or if the interaction method is too monotonous, it will seriously affect the enthusiasm of the learner and fail to achieve the teaching effect. By the interaction between teachers and students, students and students, and other diversified interactive design, it can promote collaborative learning, helping to train teamwork and communication skills. The interaction between teachers and students can enable learners to get timely feedback and adjust the pace of learning in a timely manner to improve learning efficiency and quality.

IV. IDEAS ON THE CONSTRUCTION OF ONLINE COURSE INSTRUCTIONAL DESIGN BASED ON LEARNERS' PERSPECTIVE

Good instructional design can lead to effective course learning. In the university online courses, the instructional design refers to the reasonable arrangement and organization of the elements involved in the course according to the requirements of the course and the characteristics of the students, so as to promote the smooth progress of learning activities. At present, China online education mostly stays in the condition of moving traditional teaching methods and teaching materials mechanically to the Internet as a course for online education, using non-differentiated teaching for learners, which generally manifest the lack of innovation and pertinence in the instructional design and arrangement of online courses. For students in applied universities, this kind of online education is not attractive, which will greatly reduce their learning enthusiasm. Therefore, the online course design should be truly in line with the learner's learning habits and meet the learner's learning needs. This paper proposes the idea of online course instructional design from the perspective of learners as shown in Fig. 1. 


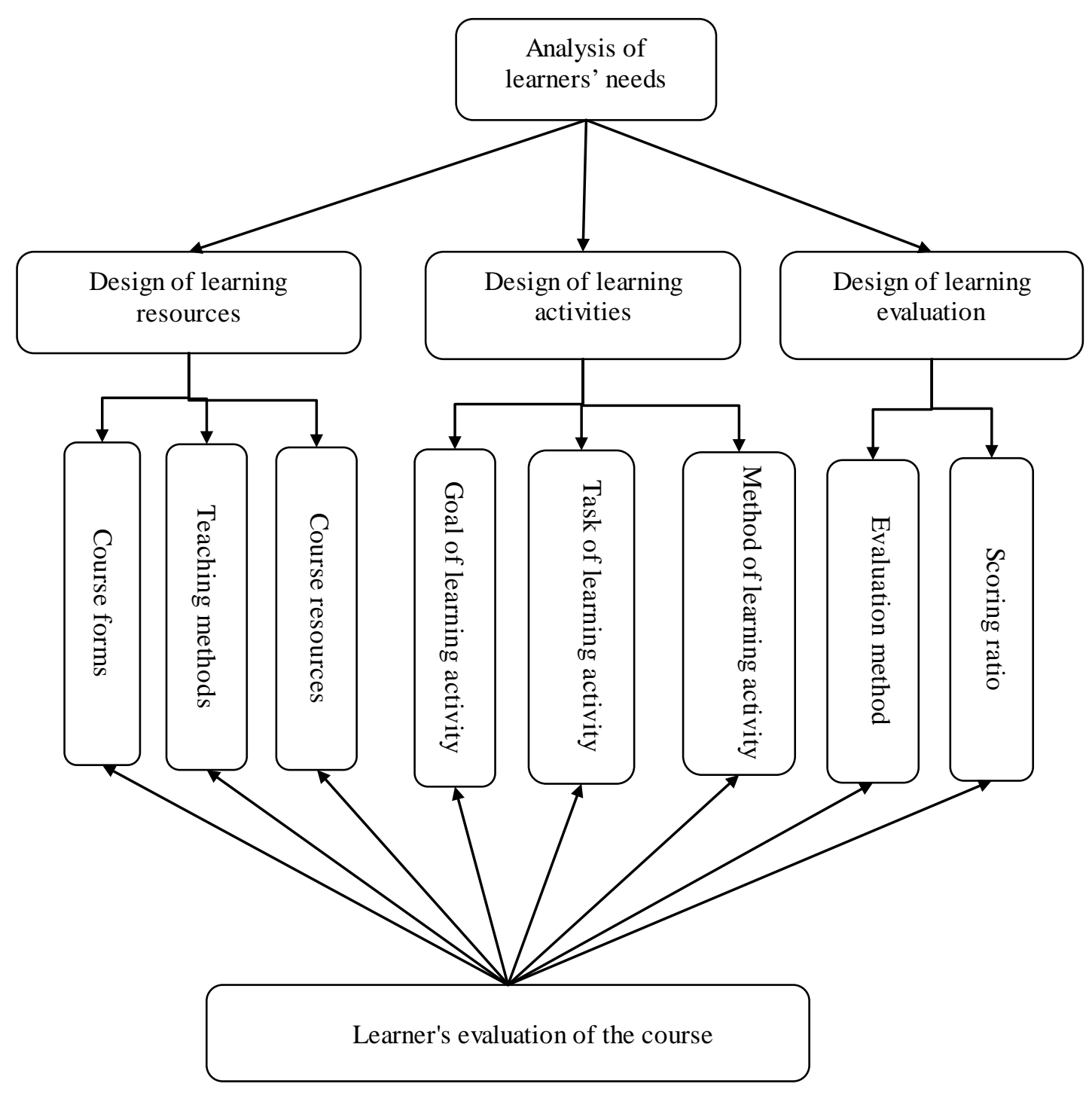

Fig. 1. The idea of online course instructional design from the perspective of learners

\section{A. Analysis of learners' needs}

The purpose of teaching is to help people learn. Instructional design must help learners acquire the appropriate knowledge and abilities. The first step in instructional design for online courses should be learner's needs oriented and understand the purpose of the learner's studying course. The analysis of the learner's needs mainly depends on whether the content provided by the course is consistent with the learner's needs, whether the difficulty level of the course is consistent with the learner's learning level. And it is necessary to clarify the learning method that the learner is interested in. In-depth researches on the needs of learners are conducive to the formation of a correct instructional design concept and improve the professional ability of instructional design. It is also the basis for completing learning resources, learning activities and learning evaluation programs in instructional design.

\section{B. Design of learning resources of online course}

The diversity of learning resources is one of the characteristics of online courses. The design of learning resources is mainly reflected in the form of the curriculum, the teaching methods adopted by the curriculum and the presentation of curriculum resources. There are two main types of courses. One way is simply online learning and online exams, and finally to give comprehensive results. The other is the combination of online and offline forms that are currently used in professional course teaching. Teaching methods include combination with lectures and discussions, teachersteaching assistants-students discussion type, situational dialogue type, scene presentation type, teacher-student discussion type, teaching assistants question answering type and other teaching methods. Course resources mainly include video, quizzes, course discussions, lectures, extended reading, reference materials, syllabus, exercises, assignments and many other forms. For the learners in applied universities, the online courses should be based on the mix of online and offline 
teaching, with the idea of taking online learning as supplement. The presentation of teaching methods and curriculum resources should be in the way of the combination of scientificity and interesting.

\section{Design of learning activities of online course}

Online learning activities should be comprehensively designed from three aspects: learning goals, learning tasks and learning forms. Teachers are required to consider the goals and demands of talents fostering as well as the characteristics of students when they plan the learning goals, design the suitable learning tasks and learning forms. Learning tasks should be matched with learning goals, and learning forms should be helpful in finishing the learning tasks. Currently, most common learning activities include: students learn by themselves and finish the inter-class quizzes, communication in class, discussions with teachers' aid, test and homework, work display, and so on. Online learning activities in applied universities should have brief and clear goals. Learning tasks and learning forms are mostly inter-class quizzes and work display, which are convenient for students to show their characteristics. These activities can meet the needs for displaying university students' characteristics and attracting students to actively engage in.

\section{Design of learning evaluation system of online course}

When designing the online learning evaluation system, we need to design the evaluating methods and scoring rules. Online courses have diversified course resources and learning patterns, leading to diversified evaluating methods. Currently, approaches such as unit quizzes, unit homework, final exams, inter-class discussions are widely used. The score of each approach should be rationally arranged according to the teaching goals. Online courses' evaluating methods and scoring rules can effectively arouse learners' attention. When designing it, we could set the evaluating methods and scoring rules on the basis of teaching goals, and thus lead the students to finish learning tasks and realize the teaching objectives.

\section{E. Evaluation of online courses from students}

Students' evaluation of online courses is one of the most important steps to optimize the design of online education. After taking online courses, students should evaluate the level of selection and design of sub-indexes including learning resources, learning activities, learning evaluation, and provide constructive suggestions based on their needs. Evaluation from students are not only beneficial for perfecting the online course platform, but also give references to improve the design of courses, making full use of online courses' advantages.

\section{CONCLUSION}

The construction of online courses is one of the main approaches in the university teaching reform. Designing teaching methods plays a vital role in online courses. It not only affects the students' enthusiasm and initiative, but also has a close correlation to the results of university teaching reform.
Due to the fact that online courses are not restrained by time and space, they can bring flexibility to learning and good resources to share. But at the same time, it has some disadvantages such as weak constraining, few interactions between participants, and high demand for students' selflearning abilities. These drawbacks require that, when promoting online courses, universities should emphasize on promotion on teaching teams, and meanwhile, place much importance on guiding students to cultivate an active attitude and raise the awareness of their importance. We should make teachers learn and actively research the differences between online courses and traditional courses, and also make students rightly treat this new method, reasonably allocate learning time, and actively take part in various interacting activities of online courses. Also, we should not neglect the important role teaching design plays in building online courses. Based on the students' needs, we should insist on combing theories with practices, fully use the strength of modern telecommunication technologies, adopt diversified interacting methods, and carefully design the teaching resources, teaching procedure and even the teaching mode, realizing the real reform of teaching approaches and improvement of teaching effects.

\section{REFERENCES}

[1] Plasencia A, Navas N. MOOCs, the Flipped Classroom, and Khan Academy Practices: The Implications of Augmented Learning [M].Innovation and Teaching Technologies. Springer International Publishing, 2014:1-10.

[2] O'Connor K. MOOCs, institutional policy and change dynamics in higher education [J]. Higher Education, 2014, 68(5):623-635.

[3] Driscoll A, Jicha K, Hunt A N, et al. Can Online Courses Deliver Inclass Results? [J].Teaching Sociology, 2012, 40:312-331.

[4] Finger G, Capan L. MOOCs and Quality Issues: A Student Perspective [J].Acec Now Its Personal, 2014.

[5] King C, Kelder J A, Doherty K, et al. Designing for Quality: The Understanding Dementia MOOC. [J].Electronic Journal of e-Learning, 2014, 12(2): 161-171.

[6] Luo Fang, Yang Changxing, Liu Weiguo. On Teaching Design of MOOC Course--Taking "University Computer" Course as an Example [J]. Software Guide, 2014(9):183-185.

[7] Wu Nanzhong. Understanding the Course--The Inner Logic of MOOC Teaching Design [J]. E-education Research, 2015(3):29-33.

[8] Wang Meijing, Wang Hairong. Comparative Study and Enlightenment of Foreign MOOC Platform Based on Learner's Perspective [J]. Modern Educational Technology, 2014, 24(7):26-34.

[9] Chen Zhihua. Design and Application of Online Course Usefulness Evaluation Index System Based on User Experience [D]. Capital Normal University, 2014.

[10] Zhang You. Usability Evaluation of Teacher Network Training Courses based on User Experience [D]. Capital Normal University, 2014.

[11] Bai Xiaojing, Li Lei, Shan Ningzhen. Analysis of the Quality of Teaching Process of Online Courses from the Perspective of Learners [J]. Journal of Open Learning, 2015(4):32-38.

[12] Liu Mingzhuo, Zhu Zhiting. On MOOCs Teaching Design Style [J]. China Educational Technology, 2014(7):19-24.

[13] Hu Qintai, Lin Xiaofan. Service-Oriented MOOCs Analysis and Instructional Design Research [J]. China Educational Technology, 2015(1):39-43. 